Int. J. Dev. Biol. 49: 251-257 (2005)

doi: $10.1387 / \mathrm{ijdb} .041945 \mathrm{ig}$

\title{
Of birds and mice: hematopoietic stem cell development
}

\author{
ISABELLE GODIN ${ }^{*, 1}$ and ANA CUMANO ${ }^{2}$ \\ 'INSERM-U362 "Hématopoï̀se et cellules souches", Institut Gustave Roussy, Villejuif, France and \\ ${ }^{2}$ Unité du développement des lymphocytes, Institut Pasteur, Paris, France
}

\begin{abstract}
For many years it has been assumed that the ontogeny of the mammalian hematopoietic system involves sequential transfers of hematopoietic stem cells (HSCs) generated in the yolk sac blood islands, to successive hematopoietic organs as these become active in the embryo (fetal liver, thymus, spleen and eventually bone marrow). Very little was known about early events related to hematopoiesis that could take place during the 4.5 day gap separating the appearance of the yolk sac blood islands and the stage of a fully active fetal liver. Experiments performed in birds documented that the yolk sac only produce erythro-myeloid precursors that become extinct after the emergence of a second wave of intra-embryonic HSCs from the region neighbouring the dorsal aorta. The experimental approaches undertaken over the last ten years in the murine model, which are reviewed here, led to the conclusion that the rules governing avian hematopoietic development basically apply to higher vertebrates.
\end{abstract}

KEY WORDS: AGM, mouse embryo, hematopoiesis, splanchnopleura, yolk sac

The basics of hematopoietic development, as known circa 1970

The first approach to hematopoietic development, undertaken at the end of the XIXth century, was based on the observation of embryos at various development stages. The first sign of blood formation was observed in the yolk sac (YS) with the development of clusters of red cells. A careful examination of early YS established that red blood cells developed from cell aggregates initially identical in shape, the blood islands. As development proceeds, the cells bordering these aggregates flatten and adopt the morphology of endothelial cells whereas the inner cells progressively loose their connections and evolve into red blood cells. This developmental sequence led the early embryologist to hypothesise that the homogeneous aggregates in the blood islands were constituted of precursors cells able to give rise to both endothelial and hematopoietic cells, that they called hemangioblasts (His, 1900; Murray, 1932; Sabin, 1920). They also noticed that the ability to simultaneously give rise to endothelial and hematopoietic cells is restricted to the extra-embryonic compartment, as intra-embryonic vessels develop without concomitant blood cell formation.

Another major feature in hematopoietic development observed at that time was that the production of blood cells sequentially shifts from one site to another: from mid-gestation until before birth, the fetal liver (FL) is the major provider of blood cells, followed by the spleen and finally the bone marrow. The mechanism leading to blood cell production has been a matter of intense debate over the last century, some scientists believing that the generation of hematopoietic cells in the embryonic rudiments, such as the fetal liver and thymus, occurred in a similar way as observed in the early YS, while others considered that the rudiments had to be colonised by extrinsic blood cells to maintain their production. Cytological observation proved inefficient to settle this issue and it was only in the sixties that various experimental approaches, including parabiosis (Moore and Owen, 1965; Moore and Owen, 1967; Petrakis et al., 1969), organ cultures (Houssaint, 1981) and the newly developed Chick-Quail chimaera assay (Le Douarin and Jotereau, 1975)), were successfully used to answer this question. Altogether, the results of these experiments established that the hematopoietic rudiments that become successively active during the mid-gestation period only provide the environment in which extrinsic hematopoietic stem cells (HSC) settle and give rise to a differentiated progeny. When the activity of one site recedes, new migrants colonize the next site, presumably via the blood stream (Delassus and Cumano, 1996).

Abbreviations used in this paper: AGM, aorta-gonads-mesonephos; BM,bone marrow; dpc, days post-coitum; E, embryonic day; FL, fetal liver; HSC, hematopoietic stem cells; LTR, long term reconstitution (activity); P-Sp, para-aortic splanchnopleura; S, pairs of somite; Sp, splanchnopleura; YS, yolk sac.

\footnotetext{
*Address correspondence to: Dr. Isabelle Godin. INSERM-U362 "Hématopoïèse et cellules souches", Institut Gustave Roussy-PR1, 39, Rue Camille Desmoulins, 94805 Villejuif, France. Fax: +33-1-4211-5240. e-mail: igodin@igr.fr
} 
In the mouse embryo, the fetal liver, which carries out the production of blood cells during the second half of the gestation, is the first rudiment to be colonised (Johnson and Jones, 1973; Johnson and Moore, 1975). This event begins at 10 days postcoitum (dpc), more precisely between 28 and 32 pairs of somite (S) (Houssaint, 1981). The thymus becomes colonized a little later. The timing of progenitor entry has not been determined as precisely as for the FL. Nevertheless, it is known that progenitor input occur between the $40-45 \mathrm{~S}$-stage (11 dpc) (Fontaine-Perrus et al., 1981; Manaia et al., 2000) and that the thymic rudiment is always lymphoid after 12 dpc (Fontaine-Perrus et al., 1981; Moore and Owen, 1967). The colonization of the spleen, initially thought to occur at $15 \mathrm{dpc}$ by the transfer of HSC from the FL via the blood stream (Metcalf and Moore, 1971; Sasaki and Matsumura, 1988), was more recently shown to starts at $13 \mathrm{dpc}$ (Godin et al., 1999). The definitive hematopoietic site, the bone marrow, is considered to be seeded by fetal liver HSC at $15 \mathrm{dpc}$, as soon as the vascularisation of bone rudiment starts (Metcalf and Moore, 1971; Ogawa et al., 1988).

\section{On the origin of hematopoietic precursors}

\section{The hypothesis}

The primordial origin of HSC that will colonise the hematopoietic rudiments, has been for a long time attributed to hematopoietic precursors from the yolk sac blood islands. Indeed, they were obvious candidates for generating these cells as, 1- the YS is the first hematopoietic site appearing in the embryo and 2- it was the only site known to generate hematopoietic cells in situ. In the 60$70 \mathrm{~s}$, the prevailing concept that hematopoietic cells are originated in the yolk sac saw experimental evidence in pioneer experiments from Moore and Metcalf in vitro assays (Moore and Metcalf, 1970) and from Weissman et al., reconstitution experiments. In vitro assays that allow the development of myeloid and erythroid cells were established based on the discovery of soluble mediators with a potent proliferative capacity on precursors of these lineages. Clonal assays based on the use of viscous media supplemented with growth factors were used to quantify the numbers of myeloid precursors in a given organ. It was thus shown that hematopoietic colonies were first detected in the yolk sac starting at $7.5 \mathrm{dpc}$ and only two days later, well after the establishment of circulation, in the embryo proper. Weissman et al., transplanted YS cells isolated from 8 to $10 \mathrm{dpc}$ embryos into the YS cavity of isochronic hosts bearing different surface markers ( $\mathrm{H}-2$ or Thy-1). The progeny of donor cells was traced by allotypic markers and donor derived thymocytes were readily detected, albeit at low frequency, in the recipient mice (Weissman et al., 1978).

\section{The test: YS-Chimaeras}

The hypothesis of a YS origin of HSC, that will contribute to lifelong maintenance of hematopoietic cell production, was first tested at stages strictly anterior to the establishment of vascular connexions between the YS and embryo body in the Avian model, by F. Dieterlen's team in the early seventies.

Yolk sac chimeras were constructed by engrafting the prospective intra-embryonic region of an E2 quail embryo on the extra-embryonic YS of a chick before initiation of blood cell circulation between the two compartments (Dieterlen-Lièvre, 1975). The analysis of the nature (donor versus host) of blood cells in the chimaeras, based on the use of the quail nucleolar marker (Le Douarin, 1969), demonstrated that the precursors that first appear in the chicken YS do not display extensive self-renewal since they are progressively replaced by a new population of Quail HSCS generated in the intra-embryonic compartment (Dieterlen-Lièvre, 1975). These intra-embryonic HSCs were found responsible for the colonization of hematopoietic rudiments and for the development of definitive hematopoiesis. Cytological (DieterlenLièvre and Martin, 1981) and in vitro analyses pointed to the region neighbouring the dorsal aorta as the source of the colonising cells.

A similar pattern of hematopoietic development was thereafter demonstrated in amphibia. In this group also, HSC responsible for definitive hematopoiesis do not originate in the ventral blood island, a structure homologous to the YS of amniotes, but from a dorsal region that encompasses the pronephros, liver and dorsal aorta (Reviewed in (Turpen, 1998)). However, lymphopoiesis in some species from this group (Xenopus Laevis) seems to depend on a contribution of precursors from both sites (Bechtold et al., 1992).

\section{What about mammals?}

First evidence for intra-embryonic hematopoietic precursors

Somewhat earlier, Herzenberg et al., had used YS and different parts of $9 \mathrm{dpc}$ embryos to reconstitute lethally irradiated recipient mice (Tyan and Herzenberg, 1968). It was shown that the subdiaphragma half of the embryo was particularly efficient to generate B-lymphocytes carrying the allotypic marker of donor cells. Although these experiments were done using embryos after the establishment of circulation, the differences of B-cell reconstitution levels obtained between the YS and embryo proper, together with the specific location of the lymphocyte precursors within the embryo proper raised the possibility that this compartment could harbours a source of hematopoietic cells.

The identification of culture conditions allowing the development and expansion of cells of the B-lineage from very immature precursors provided additional evidence that the embryo body could generate lymphocyte precursors before the onset of fetal liver hematopoiesis. In the late eighties, $9.5 \mathrm{dpc}$ embryos were isolated from the YS and dissociated cells were cultured with interleukin 7 and stromal cells, before monitoring the development of B-lineage cells. Both the YS and the embryo proper comprised lymphocyte precursors although they first appeared in the latter site (Ogawa et al., 1988).

In the early nineties, YS and embryo proper were dissociated, starting at $10 \mathrm{dpc}$ and a clonal $\mathrm{B}$ cell analysis was performed. The results obtained showed that the first precursors capable to generate B-cells in vitro were indeed located in the embryo proper rather than in the YS and that the precursors capable to generate these colonies were in an undifferentiated state, in that they had not yet started rearrangement in the immunoglobulin locus (Cumano et al., 1993).

The first direct evidence, in mammals, that lymphocyte precursors could be found in the para-aortic splanchnopleura and not in the YS came from grafting experiments where these embryonic region were placed under the kidney capsule of SCID mice. The paraaortic splanchnopleura (Figure 1: P-Sp) was tested as a possible source of HSC as it is the region homologous to early Avian aorta, previously shown to harbours intra-embryonic HSCs. Donor 
lymphocytes were detected in the recipient mice grafted with P-Sp, long after engraftment. YS cells were unable to reconstitute the lymphoid compartment in this experimental set-up (Godin et al., 1993). By the same time, Medvinsky et al., showed that cells isolated from the region that comprise the Aorta, Gonads and Mesonephros (AGM region, a later development stage of the P-Sp: Figure 1) displayed CFU-S activity, indicating the existence of multilineage hematopoietic precursors in this region of the pre-liver embryos (Medvinsky et al., 1993).

The ability of hematopoietic precursors from the P-Sp to generate both myeloid and lymphoid cells, a capacity which correlates with long-term reconstituting activity in stem cells, was demonstrated in vitro at the single cell level (Godin et al., 1995). Micro-manipulated P-Sp cells were shown to develop into myeloid cells of different types, as well as B and T lymphocytes (when the expanded progeny was placed in irradiated fetal thymic lobes). Muller et al., subsequently reported that long-term reconstitution capacity was present in AGM precursors at $10.5 \mathrm{dpc}$, shortly before the detection of this capacity in YS, at $11 \mathrm{dpc}$ (Muller et al., 1994).

\section{Origin of intra-embryonic hematopoietic precursors}

The experiments described above allowed for the identification of an intra-embryonic site enriched for HSC, but could not lead to any conclusion about the site of origin of these cells. As the vascular system is fully developed at the stage when the P-Sp/ AGM were analysed, this enrichment could either results from an in situ de novo generation of HSC or from the aggregation of precursors born elsewhere (presumably in the YS), that would found in the P-Sp/ AGM a environment suitable to express their potential.

To address the question of the intraembryonic precursors site of origin, it was thus necessary to assess the hematopoietic potential of the P-Sp/AGM before circulation is established between the extra- and intra-embryonic compartments (at $8 \mathrm{dpc}$ ). However, our first experiments clearly established that no hematopoietic precursors were present in the intra-embryonic compartment before $8.5 \mathrm{dpc}$ (Godin et al., 1995).

We overcame this limitation by explanting the presumptive P-Sp/AGM territory (the caudal intra-embryonic splanchnopleura: $S p)$ and the corresponding $\mathrm{YS}$, at pre-circulation stages (Figure 1). We maintained the explants in organ culture for 2 to 4 days in order to allow the determination of hematopoietic precursors, before analysing the presence of hematopoietic precursors in individual Sp explants and their YS counterpart. This experiment brought up the following results (Cumano et al., 1996):

1- Pre-circulation Sp display a hemogenic potential, as they were able to give rise to hematopoietic cells when severed from the YS. Intraembryonic precursors thus appear to result from an in situ determination of mesodermal cells, independent from that which occurs in the YS.

2- $\quad$ No hematopoietic progeny was ever detected in the embryos deprived from both the Sp and YS. The intra-embryonic hematopoietic determination event is thus restricted to the caudal intra-embryonic splanchnopleura, which will further evolve into PSp/AGM.

3- The differentiation potential of the YS and Sp from individual embryos revealed striking differences between the hematopoietic precursors derived from the two compartments. Unlike the splanchnopleura, the YS proved unable to generate a lymphoid progeny, an observation independently documented later by (Nishikawa et al., 1998). It also displayed a reduced potential for maintenance and differentiation of myeloid lineage progenitors.

However, these early intra-embryonic hematopoietic precursors did not display in vivo engraftment capacity when transplanted into adult irradiated recipients (Cumano et al., 1996). As MHC class I molecules are expressed at low levels in all cells from the embryo before $10.5 \mathrm{dpc}$ (Jaffe et al., 1991), we considered that hematopoietic precursors could therefore be eliminated by radiation resistant host NK cells. We tested this possibility by transplanting hematopoietic precursors, isolated before circulation, into two mouse strains, alymphoid Rag2 ${ }^{-/-}$and Rag2 $\mathrm{\gamma c}^{-/-}$mice that also lack NK cell activity (Colucci et al., 1999). We showed that:

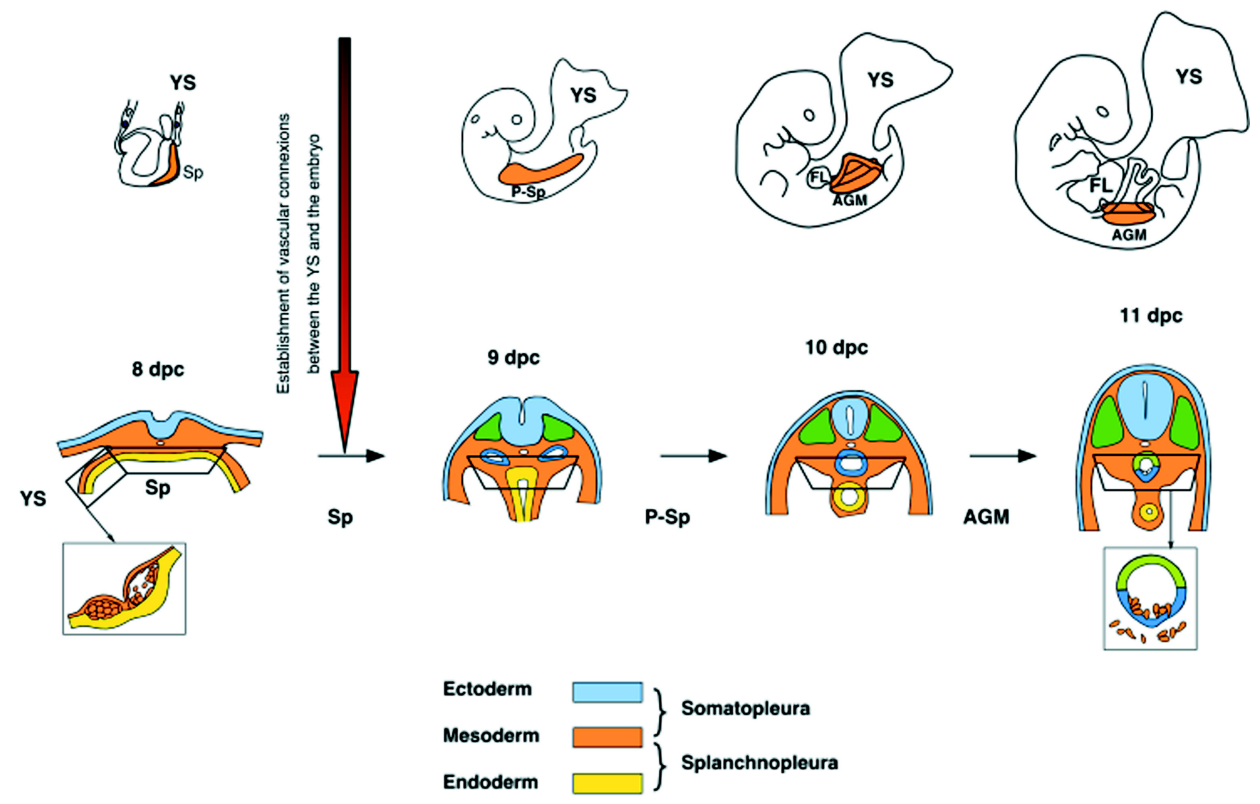

Fig. 1. Localisation and evolution of the intra-embryonic hemogenic site in the mouse embryo. The top panel shows the location in whole embryos, of the presumptive intra-embryonic hemogenic site at $8 \mathrm{dpc}$ (before the connexion of the extra-and intra-embryonic vessels: Sp) and, at later stages, of the hemogenic site derived from it, the P-Sp (8.5 to $10 \mathrm{dpc}$ ), then AGM (10 to $12 \mathrm{dpc}$ ). In the lower panel, the boxed area indicates the structure of the presumptive hemogenic site (Sp) and, between 8.5 and $11 \mathrm{dpc}$, the tissue composition of the region shown in vitro and in vivo to contain hematopoietic stem cells (P-SP/AGM). At $11 \mathrm{dpc}$, the enlargement shows the respective localisation of the hematopoietic cluster within the aorta and the sub-aortic patches. Abbreviations: FL, fetal liver; HIAC, hematopoietic intra-aortic clusters; SAP, sub-aortic patches. 
1- $\quad$ YS precursors could engraft Rag $2 \mathrm{\gamma c}^{-/-}$recipient mice and transiently colonise the myeloid compartment. However, no lymphoid progeny was ever observed and myeloid cells could no longer be detected in the recipient mice 3 months after reconstitution;

2- $\quad$ Sp derived cells generated myeloid and lymphoid cells that could be detected in the periphery and in the bone marrow of NK deficient mice up to 8 months after transfer;

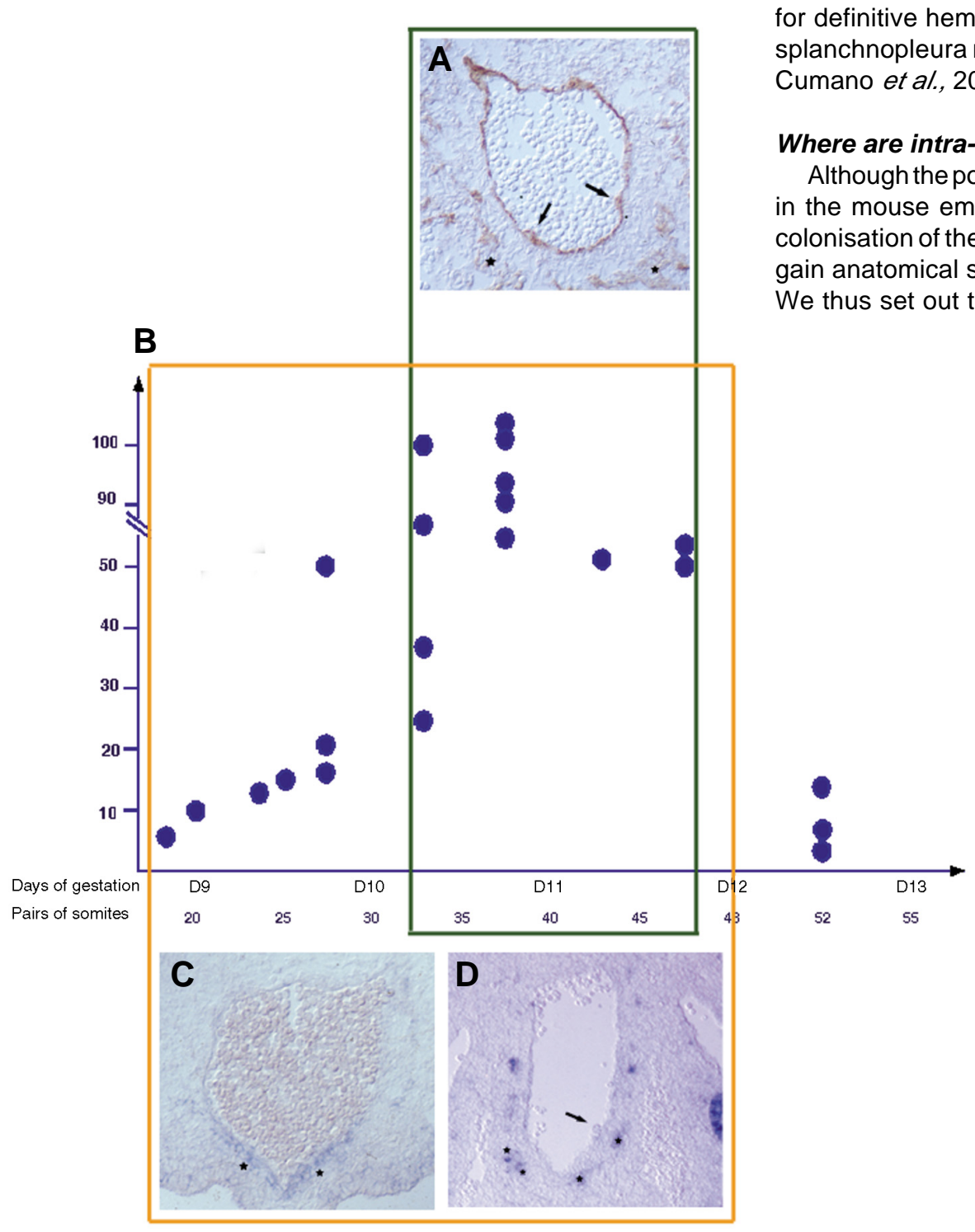

Fig. 2. Structure of the aortic region during the phase of generation of hematopoietic intra-embryonic aortic clusters: Whereas aortic clusters are detected only when intraembryonic HSC production reaches its maximal level $(10.5-11.5 \mathrm{dpc})$, the sub-aortic patches are present from the beginning to the end of the generation process $(8.5-12.5 \mathrm{dpc})$. (A) Intraaortic cluster (arrow) labelled with the AA4. 1 antibody. AA4.1 antigen expression is shared by endothelial and hematopoietic cells. (B) Numeration of multipotent hematopoietic precursors in the intra-embryonic hemogenic site between 8.5 and $13 \mathrm{dpc}$. (C,D) Sub-aortic patches are revealed by GATA-3 expression. During the P-Sp stage (8.5-10 dpc: C), the sub-aortic patches appear as layer close to the aortic floor. At the AGM stage (10.5-11.5 dpc: D), it consist of several patches often located below the aortic cluster (arrow). Notice that endothelial cells do not express GATA-3.
3- Comparison of the reconstitution capacity of these two types of hematopoietic precursors into Rag2 ${ }^{-/-}$versus $\mathrm{Rag} 2 \mathrm{\gamma c}^{-/-}$ mice indicated that the absence of NK cell activity favours the engraftment capacity of embryonic cells.

We concluded that the first HSC originate in the intra-embryonic mesoderm and that YS cells are deprived of lymphocyte differentiation capacity (Cumano et al., 2001).

These results, established from tissues isolated before blood circulates, led us to conclude that, in the mouse embryo, precursors definitive hematopoiesis are independently generated in the splanchnopleura rather than in the yolk sac (Cumano et al., 1996;

\section{here are intra-embryonic HSCs generated?}

the potential of the intra-embryonic precursors present support for their distribution within the embryo. pinpoint more precisely the site of precursor production within the P-Sp/AGM, by subdividing it into its various components and looking for precursor enrichment in vitro. We found that the isolated aorta and surrounding tissue harboured the majority of AGM multipotent hematopoietic precursors (Godin et al., 1999). Using a similar experimental approach in an in vivo assay, it was later established by $E$. Dzierzak's group that the highest frequency of Long Term Reconstitution (LTR) activity was found in the aorta region rather than in the urogenital compartment (de Bruijn et al., 2000).

When searching for cytological evidence of a hemogenic site in pre-liver embryos (8.5 to $12 \mathrm{dpc}$ ), we uncovered two structures that appear involved in the process of intraembryonic HSC production.

\section{Aortic clusters}

Cell clusters strikingly homologous to the intra-aortic clusters of the avian embryo (Dieterlen-Lièvre and Martin, 1981; Jaffredo et al., 1998; Pardanaud et al., 1989), were seen inserted inside the wall of the aorta, omphalomesenteric and umbilical arteries (Garcia-Porrero etal., 1995). These clusters are precisely located on the side of the vessel closest to the coelomic cavity, for example the ventral side of the dorsal aorta. Well-developed clusters display a mushroom shape, with round cells bulging into the lumen of the vessel. The base of the mushroom is built of bottle-shaped cells inserted between endothelial cells, thus creating a discontinuity in the endothelial layer. The basal membrane is also disrupted at the level of this stalk, as seen in an ultrastructural study (Garcia-Porrero et al., 
1995). These clusters are present in the embryo from 10.5 to 11.5 $\mathrm{dpc}$ in the AMG region. No signs of the presence of hematopoietic precursors could be disclosed before this stage, even though in vitro studies clearly established the presence of multipotent hematopoietic progenitors in the P-Sp of 8-10 dpc embryos (Figure 2B) (Godin et al., 1995).

These clusters are similar to those previously detected in birds (Dieterlen-Lièvre and Martin, 1981; Jaffredo et al., 1998; Pardanaud et al., 1989), in human embryos (Tavian et al., 1996) and, more recently, in Zebrafish (Thompson et al., 1998) and amphibian embryos (Ciau-Uitz et al., 2000).

To assess whether these intra-arterial clusters were hematopoietic, we analysed their phenotype based on the expression of immature hematopoietic cell surface markers such as CD34 or AA4.1 (Figure 2A) (Garcia-Porrero et al., 1998; Petrenko et al., 1999). These markers also label endothelial cells and reversibly, endothelial markers are often expressed by primitive hematopoietic precursors. The hematopoietic nature of aortic clusters could only be demonstrated through the lack of expression of von Willebrand factor, an endothelial marker expressed from the earliest stages of blood vessel development (Garcia-Porrero et al., 1998). These observations extended to the mouse embryo a conclusion already drawn for the aortic clusters in human embryos (Tavian et al., 1996). However, the expression analysis of the pan-hematopoietic marker CD45 led to results slightly different form those obtained in the avian (Jaffredo et al., 1998; Ody et al., 1999) and human (Tavian et al., 1996) embryos: in those two species, the aortic clusters appear completely labelled by CD45 antibodies, whereas in mouse, only a few cells of the clusters express this marker (Manaia et al., 2000; Corbel and Salaun, 2002).

\section{Sub-aortic patches}

In the course of this immunochemical analysis of the intraaortic clusters, we did not detect prospective hematopoietic precursors in situ, before the appearance of the aortic clusters, even though we know, based on the above-mentioned in vitro analyses, that multipotent hematopoietic precursors are present in the P-Sp from the $15 \mathrm{~S}$-stage (Godin et al., 1995). A likely explanation for this failure is that the number of precursors generated between 8.5 and $10 \mathrm{dpc}$ is too low (about 10 at $9 \mathrm{dpc}$ to 30 at $10 \mathrm{dpc}$, see Figure 2B) to be detected in sections.

However, when looking at the expression pattern of several transcription factors expressed by early hematopoietic precursors, a new embryonic structure located below the aortic floor was uncovered due to the expression of the GATA-3 transcription factor (Manaia et al., 2000) and AA4.1 antigen (Petrenko et al., 1999). A direct relationship between these GATA-3 positive subaortic patches and HSC generation is suggested by the fact that these structures (Manaia et al., 2000):

1- are present below the aorta for the whole duration of intraembryonic hematopoietic precursor generation, as opposed to intra-aortic clusters that are only detected at the peak of intraembryonic HSC production (Figure 2C, D),

2- are restricted to the ventral aspect of the aorta, that bears the hematopoietic clusters (Figure 2C, D),

3- are preferentially located under the intra-aortic hematopoietic clusters (Figure 2D),

4- are better defined at 10.5-11.5 dpc when intra-aortic hematopoietic clusters are detected and their number is at its highest (Figure 2C, D),

5- disappears after $12.5 \mathrm{dpc}$, when intra-embryonic precursors are no longer generated (Godin et al., 1999).

A similar structure has also been described in the human AGM, which has been shown to express various factors, such as Tenascin C (Marshall et al., 1999), Smooth Muscle Actin (Tavian et al., 1999) and the adhesion molecule HCA (Cortes et al., 1999).

The function played by these sub-aortic patches in the process of intra-embryonic HSC generation is still unclear. However, the following model for intra-embryonic stem cell generation, which takes in account the spatio-temporal relationship between the presence in the embryo of aortic clusters and sub-aortic patches and in evolution of intra-embryonic HSC number, as determinedin vitro (Godin et al., 1995), may be proposed (Figure 2):

Intra-embryonic HSC would be generated within the sub-aortic patches, a composite structure including both the newly born HSCs and the environment suitable for their generation. The HSC would migrate to the aortic floor and translocate into the circulation to colonise the fetal hematopoietic rudiments. This translocation process would lead to the formation of the intra-aortic clusters at the time when the number of generated HSC is the highest (between 10.5 and $11.5 \mathrm{dpc}$ ). Before this stage, it would be undetectable due to the minute number of precursors per embryo. Such a scheme is supported by preliminary data correlating the phenotype, in vivo and in vitro properties of early HSCs with the in situ gene and protein expression pattern of the sub-aortic patches.

\section{Conclusion}

The general picture emerging from the studies described above is that hematopoietic HSC are generated once in the lifetime of mammals, in the intra-embryonic compartment. However, two events of mesoderm determination towards a hematopoietic fate occur independently in two distinct anatomical sites. The YS is the first to support hematopoietic cell development, between 7 and 11 dpc. Hematopoietic precursors in the YS are apparently restricted to the erythroid lineage and to rare myeloid precursors that do not differentiate in situ. YS erythrocytes are defined as primitive due to the expression of embryonic hemoglobin and to the presence of a nucleus. Between 8.5 and $12.5 \mathrm{dpc}$, the intra-embryonic compartment defined as P-Sp/AGM harbours the first hematopoietic stem cells endowed with multipotent differentiation capacity and long-term reconstitution potential. These primordial hematopoietic stem cells seem to originate in specialized structures called subaortic patches where environmental interactions might be crucial in the generation process.

\section{References}

BECHTOLD, T.E., SMITH, P.B. and TURPEN, J.B. (1992) Differential stem cell contributions to thymocyte succession during development of Xenopus laevis. $J$ Immunol, 148: 2975-2982.

CIAU-UITZ, A., WALMSLEY, M. and PATIENT, R. (2000) Distinct origins of adult and embryonic blood in Xenopus. Cell, 102: 787-796.

COLUCCI, F., SOUDAIS, C., ROSMARAKI, E., VANES, L., TYBULEWICZ, V.L. and DI SANTO, J.P. (1999) Dissecting NK cell development using a novel alymphoid mouse model: investigating the role of the c-abl proto-oncogene in murine NK cell differentiation. J Immunol, 162: 2761-2765. 
CORBEL, C. and SALAUN, J. (2002) allb Integrin Expression during Development of the Murine Hemopoietic System. Dev. Biol. 243: 301-311

CORMIER, F. and DIETERLEN-LIEVRE, F. (1988) The wall of the chick embryo aorta harbours M-CFC, G-CFC, GM-CFC and BFU-E. Development, 102: 272285.

CORTES, F., DESCHASEAUX, F., UCHIDA, N., LABASTIE, M.C., FRIERA, A.M., HE, D., CHARBORD, P. and PEAULT, B. (1999) HCA, an immunoglobulin-like adhesion molecule present on the earliest human hematopoietic precursor cells, is also expressed by stromal cells in blood-forming tissues. Blood, 93: 826837.

CUMANO, A., DIETERLEN-LIÈVRE, F. and GODIN, I. (1996) Lymphoid potential, probed before circulation in mouse, is restricted to caudal intraembryonic splanchnopleura. Cell, 86: 907-916.

CUMANO, A., FERRAZ, J.C., KLAINE, M., DI SANTO, J.P. and GODIN, I. (2001) Intraembryonic, but not yolk sac hematopoietic precursors, isolated before circulation, provide long-term multilineage reconstitution. Immunity, 15: 477 485.

CUMANO, A., FURLONGER, C. and PAIGE, C. (1993) Differentiation and characterisation of $\mathrm{B}$-cell precursors detected in the yolk sac and embryo body of embryos beginning at the 10-12 somite stage. Proc. Nat. Acad. Sci. USA, 90: 6429-6433.

DE BRUIJN, M.F., SPECK, N.A., PEETERS, M.C. and DZIERZAK, E. (2000) Definitive hematopoietic stem cells first develop within the major arterial regions of the mouse embryo. EMBO J, 19: 2465-2474.

DELASSUS, S. and CUMANO, A. (1996) Circulation of hematopoietic progenitors in the mouse embryo. Immunity, 4: 97-106.

DIETERLEN-LIÈVRE, F. (1975) On the origin of haemopoietic stem cells in the avian embryo: an experimental approach. J. Embryol. Exp. Morphol., 33: 607619.

DIETERLEN-LIÈVRE, F. and MARTIN, C. (1981) Diffuse intraembryonic hemopoiesis in normal and chimeric Avian development. Dev. Biol. 88: 180191.

FONTAINE-PERRUS, J.C., CALMAN, F.M., KAPLAN, C. and LE DOUARIN, N.M. (1981) Seeding of the 10-day mouse embryo thymic rudiment by lymphocyte precursors in vitro. J. Immunol., 126: 2310-2316.

GARCIA-PORRERO, J.A., GODIN, I.E. and DIETERLEN-LIÈVRE, F. (1995) Potential intraembryonic hemogenic sites at preliver stages in the mouse. Anat. Embryol., 192: 425-435.

GARCIA-PORRERO, J.A., MANAIA, A., JIMENO, J., LASKY, L.L., DIETERLENLIEVRE, F. and GODIN, I.E. (1998) Antigenic profiles of endothelial and hemopoietic lineages in murine intraembryonic hemogenic sites. Dev Comp Immunol, 22: 303-319

GODIN, I., DIETERLEN-LIĖVRE, F. and CUMANO, A. (1995) Emergence of multipotent hematopoietic cells in the yolk sac and paraaortic splanchnopleura in mouse embryo, beginning at 8.5 days postcoitus. Proc. Natl. Acad. Sci. USA, 9:, 773-777.

GODIN, I., GARCIA PORRERO, J.A., COUTINHO, A., DIETERLEN.-LIEVRE, F. and MARCOS, M.A.R. (1993) Paraaortic splanchnopleura contains B1a lymphocyte precursors. Nature, 364: 67-69.

GODIN, I., GARCIA-PORRERO, J.A., DIETERLEN-LIEVRE, F. and CUMANO, A. (1999) Stem cell emergence and hemopoietic activity are incompatible in mouse intraembryonic sites. J Exp Med, 190: 43-52.

HIS, W. (1900) Lecithoblast und angioblast der wirbelthiere. Abhandl. Ks Ges Wiss Math Phys, 22: 171.

HOUSSAINT, E. (1981) Differentiation of the mouse hepatic primordium: IIExtrinsic origin of the haemopoitic cell line. Cell Diff, 10: 243-252.

JAFFE, L., ROBERTSON, E.J. and BIKOFF, E.K. (1991) Distinct patterns of expression of MHC class I and beta 2-microglobulin transcripts at early stages of mouse development. $J$ Immunol, 147: 2740-2749.

JAFFREDO, T., GAUTIER, R., EICHMANN, A. and DIETERLEN-LIEVRE, F. (1998) Intraaortic hemopoietic cells are derived from endothelial cells during ontogeny. Development, 125: 4575-4583.

JOHNSON, G.R. and JONES, R.O. (1973) Differentiation of the Mammalian hepatic primordium in vitro: 1- Morphogenesis and the onset of haematopoiesis. J. Embryol. exp. Morphol., 30: 83-96
JOHNSON, G.R. and MOORE, M. (1975) Role of stem cell migration in initiation of mouse fetal liver haemopoiesis. Nature, 258: 726-729.

LE DOUARIN, N. (1969) Particularités du noyau interphasique chez la Caille japonaise (Coturnix coturnix japonica). Utilisation de ces particularités comme 'marquage biologique' dans les recherches sur les interactions tissulaires et les migration cellulaires au cours de l'ontogenèse. Bull. biol. Fr. Belg., 103: 435 452.

LE DOUARIN, N.M. and JOTEREAU, F.V. (1975) Tracing of cells of the avian thymus through embryonic life in interspecific chimeras. J. Exp. Med, 142: 17 40.

MANAIA, A., LEMARCHANDEL, V., KLAINE, M., MAX-AUDIT, I., ROMEO, P., DIETERLEN-LIEVRE, F. and GODIN, I. (2000) Lmo2 and GATA-3 associated expression in intraembryonic hemogenic sites. Development, 127: 643-653.

MARSHALL, C.J., MOORE, R.L., THOROGOOD, P., BRICKELL, P.M., KINNON, C. and THRASHER, A.J. (1999) Detailed characterization of the human aortagonad-mesonephros region reveals morphological polarity resembling a hematopoietic stromal layer. Dev Dyn, 215: 139-147.

MEDVINSKY, A.L., SAMOYLINA, N.L., MULLER, A.M. and DZIERZAK, E.A (1993) An early pre-liver intraembryonic source of CFU-S in the developing mouse. Nature, 364: 64-67.

METCALF, D. and MOORE, M.A.S. (1971) Embryonic aspects of haemopoiesis. In A. Neuberger et E.L. Tatum Eds (ed.), Haematopoietic cells. North Holland Publish. Co., Amsterdam, London, Vol. 24, pp. 173-271.

MOORE, M.A.S. and METCALF, D. (1970) Ontogeny of the haematopoietic system: Yolk sac origin of in vivo and in vitro colony forming cells in the developing mouse embryo. Brit. J. Haematol., 18: 279-296.

MOORE, M.A.S. and OWEN, J. (1965) Chromosome marker studies on the development of the haemopoietic system in the chick embryo. Nature, 208: 956989

MOORE, M.A.S. and OWEN, J. (1967) Experimental studies on the development of the thymus. J. Exp. Med., 126: 715-725.

MULLER, A.M., MEDVINSKY, A., STROUBOULIS, J., GROSVELD, F. and DZIERZAK, E. (1994) Development of hematopoietic stem cell activity in the mouse embryo. Immunity, 1: 291-301

MURRAY, P. (1932) The development «in vitro» of blood of the early chick embryo. Proc. Roy. Soc., 111: 497-521.

NISHIKAWA, S.I., NISHIKAWA, S., KAWAMOTO, H., YOSHIDA, H., KIZUMOTO, M., KATAOKA, H. and KATSURA, Y. (1998) In vitro generation of lymphohematopoietic cells from endothelial cells purified from murine embryos. Immunity, 8: 761-769.

ODY, C., VAIGOT, P., QUERE, P., IMHOF, B.A. and CORBEL, C. (1999) Glycoprotein Ilb-Illa is expressed on avian multilineage hematopoietic progenitor cells. Blood, 93: 2898-2906.

OGAWA, M., NISHIKAWA, S., YAMAMURA, F., NAITO, M. and TAKAHASHI, K. (1988) B cell ontogeny in murine embryo studied by a culture system with the monolayer of a stromal cell clone, ST2: B cell progenitor develops first in the embryonal body rather than in the Yolk sac. EMBO, 7: 1337-1343.

PARDANAUD, L., YASSINE, F. and DIETERLEN-LIÈVRE, F. (1989) Relationship between vasculogenesis, angiogenesis and haemopoiesis during avian ontogeny. Development, 105: 473-485

PETRAKIS, N.L., PONS, S. and LEE, R.E. (1969) An experimental analysis of factors affecting the localisation of embryonic bone marrow. In "Hemic cells in vitro», 3, Farnes.

PETRENKO, O., BEAVIS, A., KLAINE, M., KITTAPPA, R., GODIN, I. and LEMISCHKA, I. (1999) The molecular characterization of the fetal stem cell marker AA4. Immunity, 10: 691-700.

SABIN, F.R. (1920) Studies on the origin of blood-vessels and of red blood corpuscles as seen in the living blastoderm of chicks during the second day of incubation. Carnegie contribution to embryology, 27:, 214-262.

SASAKI, K. and MATSUMURA, G. (1988) Spleen lymphocytes and haemopoietis in the mouse embryo. J. Anat, 160: 27-37.

TAVIAN, M., COULOMBEL, L., LUTON, D., SAN CLEMENTE, H., DIETERLENLIEVRE, F. and PEAULT, B. (1996) Aorta-associated CD34+ hematopoietic cells in the early human embryo. Blood, 87: 67-72. 
TAVIAN, M., HALLAIS, M.F. and PEAULT, B. (1999) Emergence of intraembryonic hematopoietic precursors in the pre-liver human embryo. Development, 126: 793-803.

THOMPSON, M.A., RANSOM, D.G., PRATT, S.J., MACLENNAN, H., KIERAN, M.W., DETRICH, H.W., 3RD, VAIL, B., HUBER, T.L., PAW, B., BROWNLIE, A.J., OATES, A.C., FRITZ, A., GATES, M.A., AMORES, A., BAHARY, N., TALBOT, W.S., HER, H., BEIER, D.R., POSTLETHWAIT, J.H. and ZON, L.I. (1998) The cloche and spadetail genes differentially affect hematopoiesis and vasculogenesis. Dev Biol, 197: 248-269.
TURPEN, J.B. (1998) Induction and early development of the hematopoietic and immune systems in Xenopus. Dev. Comp. Immunol., 22: 265-278.

TYAN, M.L. and HERZENBERG, L.A. (1968) Studies on the ontogeny of the mouse immune system: II. Immunoglobulin producing cells. J. Immunol., 101: 446-450.

WEISSMAN, I., PAPAIOANNOU, V. and GARDNER, R. (1978) Fetal hematopoietic origins of the adult hemolymphoid system. In Clarkson, B., Mark, P., Till, J. (ed.), Differentiation of normal and neoplastic cells. Cold Spring Harbour Laboratory, New York, Vol. 5, pp. 33-47. 